\title{
Erratum zu: Telemedizin in der Radiologie
}

Maximilian de Bucourt 


\section{Erratum zu:}

Kapitel 12 in: G. Marx et al. (Hrsg.),

Telemedizin, $>$ https://doi.org/10.1007/978-

3-662-60611-7_12

Versehentlich wurden die vom Autor gelieferten korrigierten Abbildungen 12.1, 12.2 und 12.3 in Kapitel 12 nicht ausgetauscht. Wir bitten dies $\mathrm{zu}$ entschuldigen und haben die Abbildungen nun ersetzt.

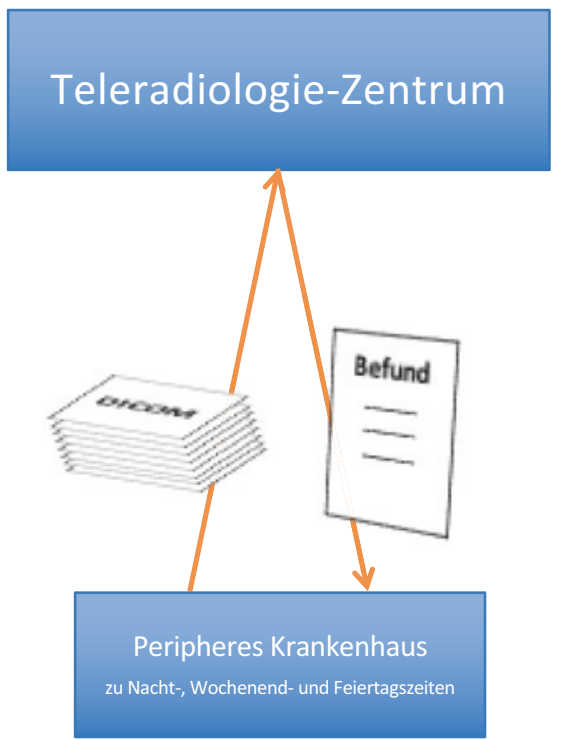

- Abb. 12.1 Prinzip der Teleradiologie. Ein peripheres Krankenhaus übermittelt Bilddaten (DICOM-Format) an ein Teleradiologiezentrum und erhält einen radiologischen Befund zu den übermittelten Bilddaten 


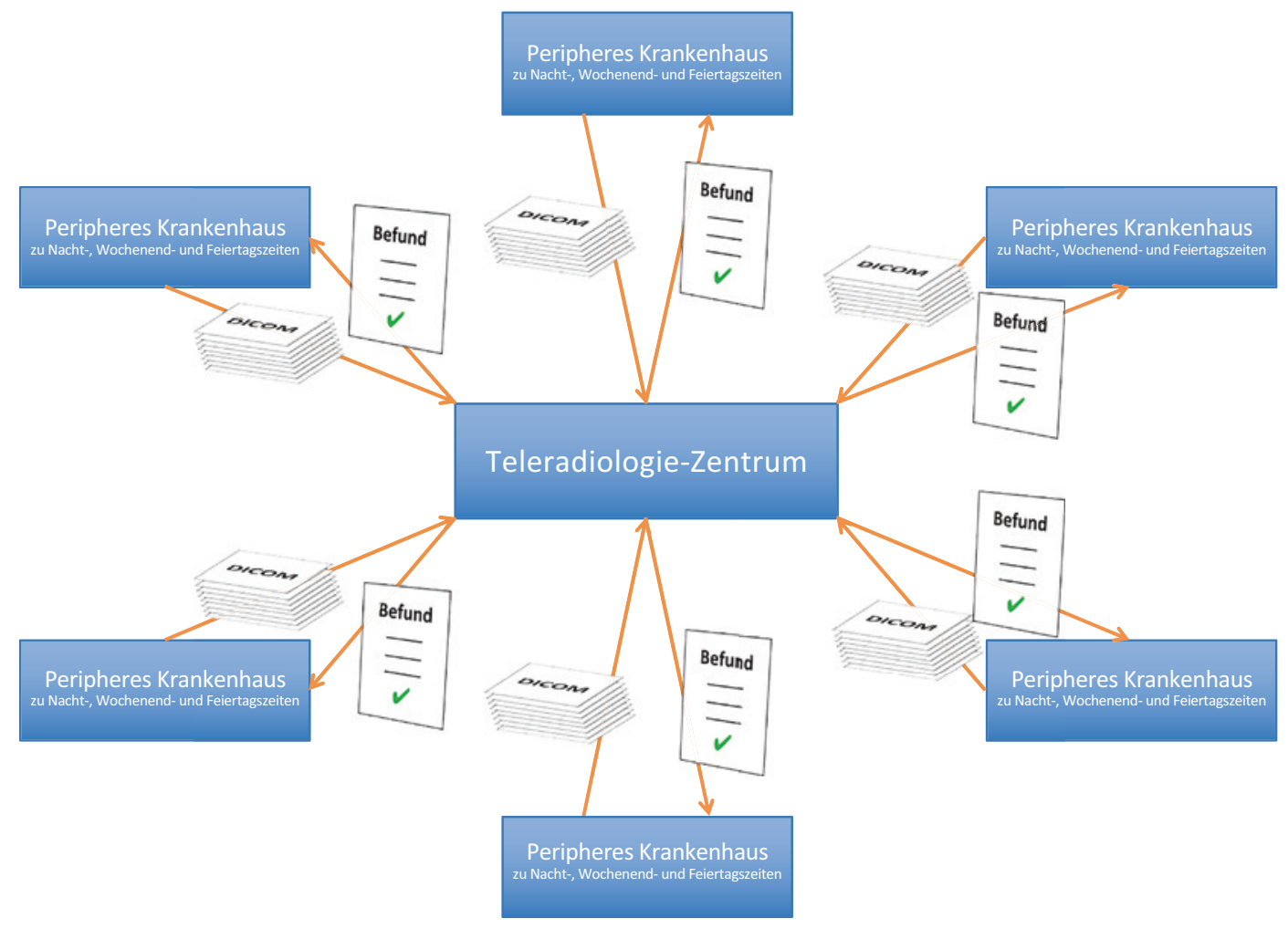

- Abb.12.2 Skalierung. Das Teleradiologiezentrum kann die Serviceleistung mehreren peripheren Krankenhäusern anbieten, was zu einer effizienteren Ressourcenallokation führen kann. Nur im Teleradiologiezentrum muss dann zu Nacht-, Wochenend- und Feiertagszeiten die radiologische Facharztexpertise vorgehalten werden 


\section{Teleradiologie-Zentrum}

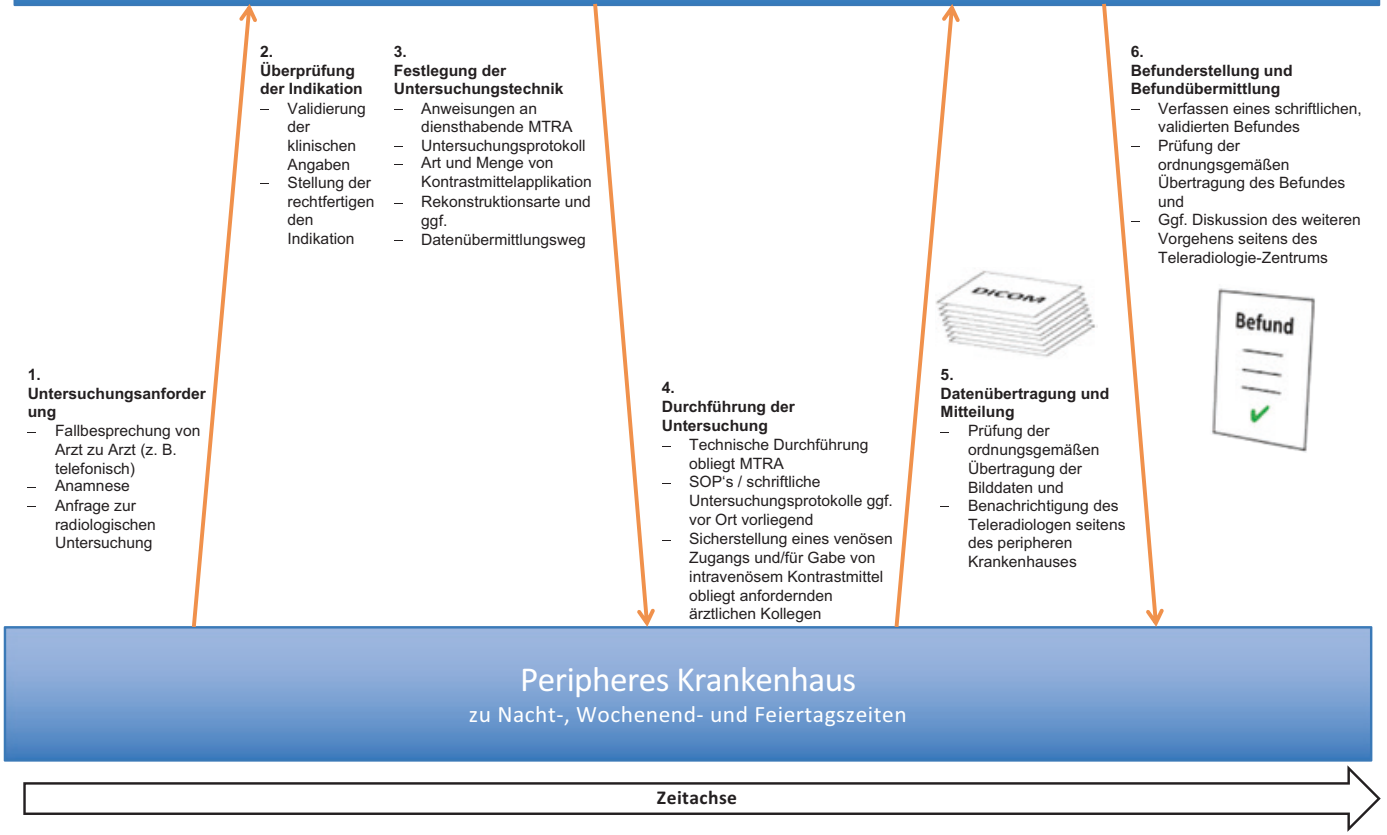

- Abb. 12.3 Teleradiologischer Workflow in 6 Schritten. MTRA Medizinisch-technischer Radiologieassistent; SOP's Standard Operating Procedures 